\title{
Management of Hypertensive Emergencies
}

\author{
Jaya Mallidi, Srikanth Penumetsa and Amir Lotfi*
}

The Division of Cardiology, Baystate Medical Center, USA

\begin{abstract}
Hypertension is a common problem encountered in everyday clinical practice. Patients with poorly controlled hypertension may present to the emergency room with "hypertensive emergency" - severely elevated blood pressure $(>180 / 120 \mathrm{mmHg}$ ) associated with end organ damage, involving neurological, cardiovascular or renal systems. There is a paucity of literature regarding the preferred rate of decline of blood pressure, while treating these patients, as well as the appropriate medications to be used. Based on expert opinion and anecdotal data, it is recommended that the initial management should focus on promptly identifying impending or established end organ damage and decreasing the blood pressure by about $25 \%$ in the first 2 hours, except in aortic dissection where rapid lowering of blood pressure is recommended. This review provides a focused approach to the management of hypertensive emergencies.
\end{abstract}

\section{Keywords: Hypertension; Emergency; Urgency}

\section{Introduction}

Hypertension is a common problem affecting 60-70 million people in the United States [1]. Two thirds of patients are unaware that they have hypertension [2]. While it is well known that poorly controlled hypertension is a major risk factor for cardiovascular and cerebrovascular mortality, acute severe elevation in the blood pressure can also cause acute end organ damage. Approximately $1-2 \%$ of all the hypertensive patients present to the emergency room with hypertensive emergency at least once in their lifetime [3]. Given the high prevalence of hypertension in our society, hypertensive emergencies are commonly encountered in everyday clinical practice [3]. Prompt recognition, evaluation and treatment are of paramount importance in preventing permanent end organ damage. The most recent periodic review by the Joint National Committee (JNC) on "Prevention, Detection, Evaluation and Treatment of High Blood Pressure", does not give explicit guidelines on the management of hypertensive emergencies [4].

This review article aims to discuss the management of hypertensive emergencies based on specific clinical situations.

\section{Definition} [4].

JNC 7 classifies blood pressure into different categories (Table 1)

Hypertensive emergency is defined as "a severe elevation is blood pressure (usually $>180 / 120 \mathrm{mmHg}$ ) complicated by impending or progressive target organ dysfunction involving neurological, cardiac or renal systems" [4]. Common clinical manifestations of end organ damage in hypertensive emergency include Acute Coronary Syndrome (ACS), acute decompensated heart failure, encephalopathy, intracerebral hemorrhage and acute renal failure. Common clinical manifestations of end organ damage in hypertensive emergency are shown in Figure 1.

Hypertensive urgency is acute severe elevation in blood pressure $(>180 / 120 \mathrm{mmHg})$ without evidence of end organ damage. The term "hypertensive crisis" is often used to include both hypertensive emergencies and urgencies.

\section{Initial Clinical Evaluation}

Patients with hypertensive emergency commonly present with new symptoms related to the target organ involved. A thorough history and physical examination should be performed and appropriate treatment strategies should be employed to address the underlying cause.

\section{History}

All patients with presenting with severe hypertension should

\begin{tabular}{|c|c|c|}
\hline Category & $\begin{array}{c}\text { Systolic Blood } \\
\text { Pressure } \mathbf{( m m H g})\end{array}$ & $\begin{array}{c}\text { Diastolic Blood } \\
\text { Pressure }(\mathbf{m m H})\end{array}$ \\
\hline Normal & $<120$ & $<80$ \\
\hline Pre-hypertension & $120-139$ & $80-89$ \\
\hline Hypertension - Stage I & $140-159$ & $90-99$ \\
\hline Hypertension - Stage II & $\geq 160$ & $\geq 100$ \\
\hline Hypertensive Emergency & $>180$ & $>120$ and end organ \\
damage
\end{tabular}

Table 1: Classification of Blood Pressure for Adults [4].

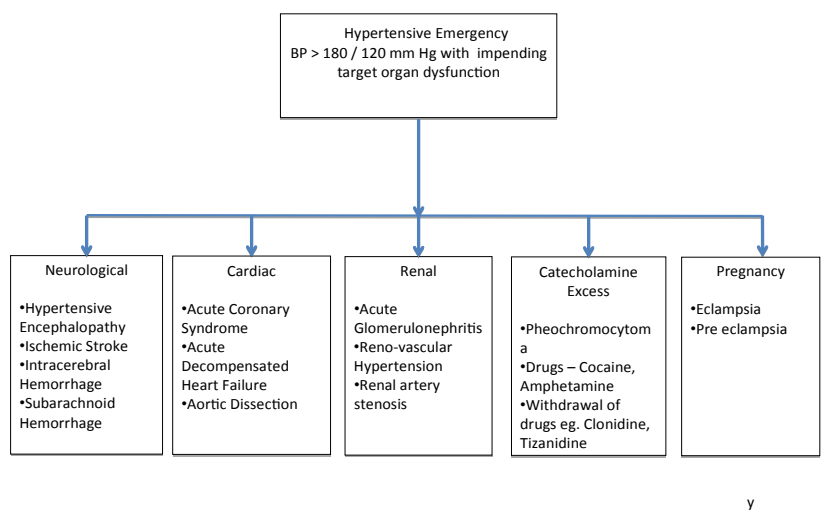

Figure 1: Common clinical scenarios associated with hypertensive emergency.

*Corresponding author: Amir Lotfi, MD, Division of Cardiovascular Medicine Baystate Medical Center, 759 Chestnut Street, Springfield, MA, 01199, USA, Fax: 1413794 0198; E-mail: amir.lotfi@bhs.org

Received May 26, 2013; Accepted June 18, 2013; Published June 20, 2013

Citation: Mallidi J, Penumetsa S, Lotfi A (2013) Management of Hypertensive Emergencies. J Hypertens 2: 117. doi:10.4172/2167-1095.1000117

Copyright: $\odot 2013$ Mallidi $\mathrm{J}$, et al. This is an open-access article distributed unde the terms of the Creative Commons Attribution License, which permits unrestricted use, distribution, and reproduction in any medium, provided the original author and source are credited. 
be assessed for acute target organ damage. Patient's hypertensive history, current medication regimen, last dose of antihypertensive medication taken and medication compliance should be obtained. History of recreational drug use (amphetamines, cocaine, monoamine oxidase inhibitors or phencyclidine) should also be explored. Attempt should be made to find out the usual blood pressure reading for each patient either at home or in the ambulatory setting before the onset of hypertensive crisis. It is important to understand that some patients with chronic hypertension always have an elevated blood pressure. In fact, a normal blood pressure of $120 / 80 \mathrm{mmHg}$, may be too low for them. Hence, a diagnosis of hypertensive emergency or urgency cannot be made based on a single absolute blood pressure reading, but is based on acute elevation of blood pressure from baseline associated with end organ damage.

\section{Examination}

Blood pressure should be evaluated in both arms with appropriately sized cuff. Physical examination should also be aimed at identifying target organ dysfunction. A focused neurological examination to assess for mental status changes and focal neurological deficits should be done. Altered mental status with fundoscopic examination revealing exudates, hemorrhages or papilledema suggests hypertensive encephalopathy [5]. Cardiovascular examination should focus on presence of pathologic gallops $\left(\mathrm{S}_{3}\right.$ and $\left.\mathrm{S}_{4}\right)$ and murmurs (e.g., aortic regurgitation). Elevated jugular venous pulsations and crackles in the lung field suggest pulmonary edema and decompensated congestive cardiac failure. Distal pulses should be palpated in all extremities, and unequal pulses should raise a suspicion for aortic dissection.

\section{Laboratory work up}

Electrocardiogram should be done to assess for left ventricular hypertrophy, arrhythmias, acute ischemia or infarction. Urinalysis should be done to assess for hematuria and proteinuria. Basic metabolic profile including assay of blood urea nitrogen and serum creatinine is important to assess for kidney dysfunction. Cardiac biomarkers should also be checked if ACS is suspected.

\section{Radiographic studies}

Patients presenting with altered mental status or focal neurological deficits should get a Computed Tomography (CT) of the brain to assess for hemorrhage or infarct. Chest $\mathrm{X}$ ray is often done to assess for pulmonary edema. If aortic dissection is suspected (based on history of chest pain, unequal pulses and/or a widened mediastinum on chest $\mathrm{X}$ ray), imaging of the aorta ( $\mathrm{CT}$ angiogram/magnetic resonance imaging/transesophageal echocardiogram) should be performed immediately [5].

\section{Initial Treatment}

The existing literature on hypertensive emergencies or urgencies does not provide robust evidence regarding a specific rate of decline in blood pressure that should be achieved in order to improve mortality and morbidity [6]. To date there are no randomized controlled trials to assess clinical outcomes, comparing different rates of decline in blood pressure among patients presenting with hypertensive emergencies [6].

Cerebral auto regulation of blood pressure is altered in hypertensive emergencies. Hence it has been postulated that rapid reduction of blood pressure might result in reduced cerebral perfusion - propagating the end organ damage [6]. Therefore, invasive arterial hemodynamic monitoring in intensive care setting with use of short acting, titratable intravenous anti-hypertensive agents is recommended in these situations [6].

The Clinical practice guidelines based on JNC 7 suggest that the mean arterial blood pressure should be reduced by $<25 \%$ within the first 2 hours and to around 160/100-110 mmHg over the next 6 hours [4]. Aortic dissection, however, is a special clinical situation where it is recommended to reduce the blood pressure to less than $120 \mathrm{mmHg}$ within 20 minutes [4]. The choice of the antihypertensive agent is often based on target organ dysfunction, availability, ease of administration, institutional culture and physician preference [7].

\section{Pharmacological management}

There are several drugs to choose from, in the management of hypertensive emergencies. No single drug has been proved to be more beneficial than the others in this clinical setting.

The following are some of the common medications used (Table 2):

Sodium nitroprusside: Sodium nitroprusside is both an arterial and venous vasodilator $[8,9]$. It results in pre load and after load reduction $[8,9]$. It is easily titratable and its effects are reversible. However, it causes decreased cerebral perfusion with increasing intracranial pressure, and hence should be cautiously used in hypertensive encephalopathy $[10,11]$. Also, in patients with coronary artery disease, it may cause a significant reduction in coronary blood flow secondary to coronary steal phenomenon [12]. In a large randomized controlled trial among patients with acute myocardial infarction and elevated left ventricular filling pressure, the use of nitroprusside within 9 hours after the onset of chest pain, resulted in increased mortality [13]. Since it is a very potent agent with rapid onset of action and short half-life, it should only be used with intra-arterial blood pressure monitoring in an intensive care setting [6].

Nitroprusside contains $44 \%$ cyanide by weight [14]. Excretion of cyanide in the form of thiocyanate requires adequate liver and renal functions. Given the potential for cyanide toxicity and need for active invasive hemodynamic monitoring with an arterial line, it is not used often as the first agent of choice in hypertensive emergencies [14].

Nitroglycerin: Nitroglycerin is a venodilator and acts as an arteriolar dilator only in high doses [15]. It reduces the blood pressure by decreasing the preload and after load at higher doses. Similar to nitroprusside, it can compromise cerebral perfusion and hence is not used in hypertensive encephalopathy. It is often the agent of choice in hypertensive emergencies associated with acute pulmonary edema or acute coronary syndromes [6].

Labetalol: Labetalol is a combined alpha adrenergic and nonselective beta-adrenergic receptor blocker [16]. It has a rapid onset of action within 2-5 minutes after IV administration and the effect lasts for about 2-4 hours [17]. It can be given both as a bolus and continuous intravenous injections without invasive blood pressure monitoring. A potential side effect could be bradycardia because of the beta blocking effect. It reduces the total systemic vascular resistance, but maintains the cerebral and coronary blood flow $[18,19]$. Hence, it is recommended by the American Stroke Association for the management of hypertension in patients who received tissue Plasminogen Activator (tPA) for stroke [20]. It is often used in pregnancy induced hypertensive emergencies as it is lipid soluble and does not cross the placenta [17,21].

Fenoldopam: Fenoldopam acts on peripheral dopamine-1 receptors resulting in peripheral vasodilatation, predominantly in the renal, cardiac and splanchnic vascular beds [22-24]. Ironically despite 


\begin{tabular}{|c|c|c|c|c|c|c|}
\hline Drug & Mechanism of Action & Dose & Onset & Duration & Clinical Situations & Precautions \\
\hline $\begin{array}{l}\text { Sodium } \\
\text { Nitroprusside }\end{array}$ & $\begin{array}{l}\text { Direct arterial and venous } \\
\text { vasodilator }\end{array}$ & $\begin{array}{l}0.25-10 \mathrm{mcg} / \\
\mathrm{kg} / \mathrm{min}\end{array}$ & $1-2 \min$ & $\begin{array}{l}\text { 3-4 minutes after } \\
\text { stopping infusion }\end{array}$ & $\begin{array}{l}\text { Used in all clinical situations of } \\
\text { hypertensive emergency. Caution in } \\
\text { neurological emergencies as it can } \\
\text { decrease cerebral blood flow and in } \\
\text { ACS can cause coronary steel. }\end{array}$ & $\begin{array}{l}\text { Elevated Intracranial pressure } \\
\text { Cerebrovascular and } \\
\text { cardiovascular insufficiency } \\
\text { Renal impairment } \\
\text { Hepatic impairment }\end{array}$ \\
\hline Nitroglycerin & Venous vasodilator & $\begin{array}{l}5-200 \mathrm{mcg} / \\
\mathrm{kg} \cdot \min \end{array}$ & $2-5 \min$ & $5-10 \mathrm{~min}$ & Commonly used for ACS and ADHF & $\begin{array}{l}\text { Concomitant use of } \\
\text { phosphodiesterase } 5 \text { inhibitors. } \\
\text { Raised intracranial pressure } \\
\text { Inferior ST-elevation myocardial } \\
\text { infarction. }\end{array}$ \\
\hline Labetalol & $\begin{array}{l}\text { Combined Alpha and beta } \\
\text { adrenergic blocker }\end{array}$ & $\begin{array}{l}\text { IV bolus: } 20 \mathrm{mg} \\
\text { over } 2 \mathrm{~min} \\
\text { Infusion: } 1-2 \\
\mathrm{mg} / \mathrm{min}\end{array}$ & $\begin{array}{l}2-5 \mathrm{~min} \\
\text { after bolus }\end{array}$ & $\begin{array}{l}2-4 \text { hours after } \\
\text { stopping infusion }\end{array}$ & $\begin{array}{l}\text { Aortic dissection, and neurological } \\
\text { emergencies }\end{array}$ & $\begin{array}{l}\text { Severe bradycardia } \\
\text { Bronchial asthma } \\
\text { Recent cocaine use } \\
\text { Pheochromocytoma } \\
\text { Acute decompensated heart } \\
\text { failure }\end{array}$ \\
\hline Fenoldopam & $\begin{array}{l}\text { Peripheral dopamine } 1 \\
\text { receptor agonist }\end{array}$ & $\begin{array}{l}0.1-1.6 \mathrm{mcg} / \\
\mathrm{kg} / \mathrm{min}\end{array}$ & $10 \mathrm{~min}$ & $\begin{array}{l}1 \text { hour after } \\
\text { stopping }\end{array}$ & $\begin{array}{l}\text { Useful in hypertensive emergencies } \\
\text { complicated by renal failure }\end{array}$ & $\begin{array}{l}\text { Sulfite allergy } \\
\text { Hypokalemia }\end{array}$ \\
\hline Nicardipine & $\begin{array}{l}\text { Dihydropyridine Calcium } \\
\text { channel blocker, } \\
\text { vasodilator }\end{array}$ & $5-15 \mathrm{mg} / \mathrm{hr}$ & $10 \mathrm{~min}$ & $2-6$ hours & $\begin{array}{l}\text { Post op hypertension and neurological } \\
\text { emergencies }\end{array}$ & $\begin{array}{l}\text { Advanced aortic stenosis } \\
\text { Renal impairment } \\
\text { Acute decompensated heart } \\
\text { failure }\end{array}$ \\
\hline Clevidipine & $\begin{array}{l}\text { Ultra short acting } \\
\text { dihydropyridine } \mathrm{Ca} \\
\text { channel blocker }\end{array}$ & $\begin{array}{l}2-16 \mathrm{mcg} / \mathrm{kg} / \\
\min \end{array}$ & $1-5 \min$ & $\begin{array}{l}5 \text { minutes after } \\
\text { stopping }\end{array}$ & $\begin{array}{l}\text { Potentially useful in most hypertensive } \\
\text { emergencies; studied extensively } \\
\text { in post operative cardiac surgery } \\
\text { patients }\end{array}$ & $\begin{array}{l}\text { Allergy to soy products and egg } \\
\text { products } \\
\text { Advanced aortic stenosis } \\
\text { Acute decompensated heart } \\
\text { failure }\end{array}$ \\
\hline Hydralazine & Direct arterial vasodilator & $\begin{array}{l}\text { IV bolus: } 10- \\
20 \mathrm{mg} \text { IV }\end{array}$ & $10-20 \mathrm{~min}$ & 1-4 hours & Pre eclampsia and eclampsia & Dissecting aortic aneurysm. \\
\hline
\end{tabular}

Table 2: Drugs used for the management of Hypertensive Emergencies [2,5,7].

decreasing the blood pressure, it increases the renal perfusion [22-24]. In several studies comparing fenoldopam to other anti hypertensive agents in hypertensive emergencies, improved creatinine clearance was observed [25-27]. Therefore, this could be a useful drug in patients with hypertensive emergencies associated with acute renal failure.

Nicardipine: Nicardipine is a second-generation dihydropyridine calcium channel blocker. It acts on L-type voltage gated calcium channels causing relaxation of the peripheral arteriolar smooth muscles [5]. It has both cerebral and coronary arterial vasodilatory properties [5]. Hence it improves cerebral perfusion and is often used in hypertensive crisis in patients who received tPA for acute stroke [28].

Clevidipine: Clevidipine is a third generation dihydropyridine calcium channel blocker, approved by the FDA in 2008 for management of hypertensive emergencies [29]. It inhibits the extracellular calcium influx through the $\mathrm{L}$ type channels, relaxing the arteriolar smooth muscle resulting in decreased peripheral vascular resistance, increased stroke volume and cardiac output [30]. Clevidipine has a rapid onset $(<1$ $\mathrm{min}$ ) and offset of action and is easily titratable [31]. It is metabolized to an inactive form by esterases in the blood and extravascular tissue and hence does not require any dose adjustments in patients with renal and hepatic dysfunction [30].

The safety and efficacy of clevidipine was assessed in the Evaluation of the Effect of Ultra-Short-Acting Clevidipine in the Treatment of Patients with Severe Hypertension (VELOCITY) [32]. Among 126 patients who presented to the emergency room or intensive care unit with hypertensive crisis ( $81 \%$ had end organ damage), $90 \%$ of patients treated with clevidipine reached their target blood pressure within 30 minutes (median time of 10.9 minutes) [32]. The blood pressure dropped lower than the pre-specified target rate only in 2 patients. The Efficacy Study of Clevidipine Assessing its Preoperative Antihypertensive Effect in Cardiac Surgery-1,2 (ESCAPE -1,2) and the Evaluation of Clevidipine in the Perioperative Treatment of
Hypertension Assessing Safety Events Trial (ECLIPSE) are randomized trials that showed clevidipine to be a safe drug in hypertensive urgencies among post cardiac surgery patients [33-35].

Hydralazine: Hydralazine is a direct arteriolar vasodilator. It is often used as an antihypertensive on a PRN basis in the inpatient setting even for asymptomatic elevation of blood pressures [36]. It has an initial latent period of 5-15 minutes followed by a precipitous fall in blood pressure, with effects lasting up to 10 hours $[37,38]$. It is not recommended for use in hypertensive crisis because of its unpredictable antihypertensive effect and difficulty in titration [39]. It is often times used in pregnancy related hypertensive crisis because it is not teratogenic and increases the uterine blood flow [7].

\section{Management of Hypertension in Specific Clinical Situ- ations}

\section{Neurological emergencies}

Hypertensive encephalopathy: In patients with hypertensive encephalopathy, cerebral vascular auto regulation is disrupted, resulting in organic brain damage [40]. Cerebral blood flow is auto-regulated within specific limits - as blood pressure increases, cerebral vasoconstriction occurs to prevent hyperperfusion $[41,42]$. However, when the mean arterial pressure is exceedingly higher than the upper limit of auto regulation (usually around $180 \mathrm{~mm} \mathrm{Hg}$ for hypertensive patients), cerebral vasodilatation occurs resulting in over perfusion $[41,42]$. Blood brain barrier is disrupted resulting in microhemorrhages and cerebral edema. Symptoms include insidious onset of lethargy, confusion, severe headache, visual disturbances and seizures, which usually resolve within 24-48 hours with lowering of the blood pressure. Retinal hemorrhages, exudates or papilledema are noted on fundoscopic examination. If not acted upon immediately, it can progress to fatal cerebral hemorrhage and death. 
The treatment should be aimed at decreasing the blood pressure by $20-25 \%$ or diastolic blood pressure to $100-110 \mathrm{mmHg}$ in the first 1-2 hours [43]. Drugs that are commonly used include nicardipine, labetalol, clevidipine and fenoldopam. Sodium nitroprusside is often used though there is a potential to increase the intracranial pressure. Rapid reduction in blood pressure is not warranted as this may cause cerebral hypo-perfusion resulting in worsening neurological status and stroke [43].

Cerebrovascular Accidents (CVA): In contrast to patients with hypertensive encephalopathy, patients with CVA present with acute focal neurological deficits. Optimal management of blood pressure in these patients has not been well established.

In patients with ischemic stroke, rapid decrease in blood pressure might result in hypo-perfusion of the peri-infarct area resulting in infarct expansion $[44,45]$. Hence, anti hypertensive treatment is held unless the diastolic blood pressure is $>120 \mathrm{mmHg}$ or systolic blood pressure is $>220 \mathrm{mmHg}[46,47]$. "Permissive" hypertension is allowed for 24-48 hours [46]. In patients who received thrombolytic, more aggressive blood pressure control (systolic blood pressure $<180 \mathrm{mmHg}$ and diastolic blood pressure $<110 \mathrm{mmHg}$ ) is recommended to prevent hemorrhagic conversion [46]. In patients with hemorrhagic stroke, American Heart Association recommends to keep the mean arterial pressure $<130 \mathrm{mmHg}$ [48].

In patients with subarachnoid hemorrhage, optimal target blood pressure is controversial. While elevated blood pressure can result in recurrent hemorrhage, rapid decrease in blood pressure may result in reduced cerebral perfusion due to arteriolar vasospasm resulting in brain ischemia. While some studies suggest maintaining mean systolic arterial pressure $15 \%$ above baseline, others suggest more aggressive approach to keep the peak systolic blood pressure $20 \%$ below baseline $[49,50]$.

If patient with cerebrovascular accidents, labetalol or nicardipine are good first choice agents as they have minimal effect on cerebral blood flow and do not lead to hypoperfusion. Nimodipine is often used in subarachnoid hemorrhage to prevent cerebral arteriolar vasospasm and hence maintains cerebral perfusion [50].

\section{Cardiac Emergencies}

Hypertensive emergency with involvement of the cardiovascular system can present as three clinical entities: Acute Coronary Syndrome (ACS), Acute Decompensated Heart Failure (ADHF) and aortic dissection.

\section{Acute coronary syndrome}

Patients with ACS typically present with precordial chest pain. The spectrum of presentation could range from unstable angina, non ST-segment elevation myocardial infarction or ST-segment elevation myocardial infarction. Electrocardiogram might show signs of left ventricular hypertrophy and/or dynamic ST-segment changes consistent with ischemia. In these patients, acute adrenergic surge results in elevated blood pressure and tachycardia and increased myocardial oxygen demand. In some patients, acute elevation of blood pressure by itself can result in supply-demand mismatch from increased cardiac workload, causing elevation in cardiac enzymes. The goal of treatment would be to gradually decrease the patients' blood pressure to optimize cardiac function and alleviate symptoms. Intravenous (IV) morphine and sublingual nitroglycerin could be administered promptly while deciding on further management. Agents such as IV nitroglycerin and IV labetalol are good choices in this situation. All these agents are anti-angina medications that decrease the cardiac workload significantly and improve symptoms. Since patients with acute cardiac ischemia are prone to developing arrhythmias, labetalol has a theoretical advantage over other agents due to its beta-blocking property. Intravenous nitroprusside is best avoided in this scenario as it could potentially worsen ischemia due to coronary steal phenomenon [12]

\section{Acute decompensated congestive cardiac failure}

Patients with ADHF usually present with acute onset of dyspnea with or without chest pain. A number of clinical scenarios can lead to $\mathrm{ADHF}$ and hypertensive emergency. Acute aortic dissection (discussed later) can involve the aortic valve and lead to acute aortic insufficiency, which can precipitate acute heart failure and pulmonary edema. Patients with underlying significant renal artery stenosis can develop acute hypertensive episodes that can lead to ADHF presenting as "flash pulmonary edema". These patients could be relatively euvolemic. Patients that have underlying systolic and/or diastolic dysfunction and a history of poorly controlled hypertension can present with an acute hypertensive episode leading to acute pulmonary edema. These patients are typically volume overloaded. Patients who present de novo with acute hypertension and "flash pulmonary edema" should be investigated for renal artery stenosis. Intravenous loop diuretics (furosemide, bumetanide and torsemide) should be administered in patients that are hypervolemic and can result in some reduction of BP. Judicious use of diuretic should be employed, particularly in patients that do not have significant volume overload as this might lead to dehydration and renal injury. Nitroprusside and nitroglycerin are excellent agents for blood pressure management in ADHF. Since nitroprusside use requires invasive blood pressure monitoring and an ICU admission, nitroglycerin is a preferred agent if these facilities are not available. Severe renal dysfunction and recent use of phosphodiesterase inhibitors could preclude the use of nitroprusside and nitroglycerin respectively. Intravenous labetalolF and nicardipine are relatively contraindicated in patients with systolic dysfunction, given their negative inotropic effect. However, they can be used if the first line agents are ineffective or contraindicated. Rapid reduction of BP by about $20 \%$ within the first hour is adequate to improve cardiac performance and further reduction to a normal $\mathrm{BP}$ can be achieved over the next 6 hours.

\section{Acute aortic dissection}

Patients with acute aortic dissection present with acute chest pain. Unequal arm blood pressure readings and/or a widened mediastinum on a chest X-ray are clues to the diagnosis. When the clinical suspicion is strong, BP management should not be delayed while awaiting definitive diagnostic workup. Unlike most other presentations, the goal in this situation is to rapidly decrease BP to a normal level. Intravenous nitroprusside is an excellent first line agent for this purpose. If this is chosen, co-administration of beta blockers is necessary [51]. Other agents that are also effective include labetalol and nicardipine. If a diagnosis of type A aortic dissection is made, the definitive management would be surgery, which should be performed promptly.

\section{Acute Kidney Injury}

Acute worsening of the renal function during the management of hypertensive emergencies is a common phenomenon, especially in patients with chronic kidney disease. This is often times secondary to a precipitous fall in the blood pressure with medications rather than 
a complication of acutely elevated blood pressure [52]. The ideal rate of lowering blood pressure for renal protection is still not known. The recommended strategy is $10-20 \%$ reduction in the mean arterial pressure during the first hour or two and then further $10-15 \%$ during the next 6-12 hours [52].

The ideal drug to use in hypertensive emergencies in patients with chronic kidney disease is controversial. Nitroprusside is often used; however it has increased risk of cyanide toxicity in patients with renal failure. Fenoldopam- the dopamine 1 agonist, has been shown to improve natriuresis, diuresis and creatinine clearance compared to nitroprusside in a few studies and is currently preferred over nitroprusside in patients with renal failure [25-27].

\section{Hypertensive Emergency during Pregnancy}

Patients with Pregnancy Induced Hypertension (PIH) can present with pre-eclampsia or eclampsia. Initial therapy with magnesium sulfate is recommended for seizure prophylaxis [53]. Delivery is the definitive treatment for eclampsia [53]. Initial reduction of blood pressure to a safe range, being very careful to avoid a precipitous fall is important to prevent cerebral hemorrhage without compromising the cerebral blood flow. The American College of Obstetricians and Gynecologists recommend keeping the blood pressure between 140$160 \mathrm{~mm} \mathrm{hg}$ and diastolic blood pressure between $90-105 \mathrm{mmHg}$ [53]. Hydralazine and oral nifedipine have been traditionally used in pregnancy induced hypertension. However, recent data suggests the use of IV labetalol or nicardipine, both of which are easily titratable, to be safe and efficacious in PIH [54-57].

\section{Hypertensive Emergency due to Catecholamine Excess}

Hypertensive emergencies due to catecholamine excess are most commonly due to the following three clinical scenarios: pheochromocytoma, monoamine oxidase inhibitor crisis and abuse of drugs such as cocaine [52]. Treatment is initiated with alpha blockers (intravenous phentolamine) and beta blockers are added only if necessary. Beta blockers should never be started first because blockade of vasodilatory peripheral adrenergic receptors can theoretically lead to unopposed stimulation of alpha adrenergic receptor, resulting in precipitous elevation of blood pressure. In cocaine induced hypertension, isolated beta blockade increases the coronary vasoconstriction, heart rate and blood pressure [52]. Adequate blood pressure control with other agents such as nicardipine, fenoldopam, verapamil or phentolamine in combination with verapamil can be used.

\section{Conclusion}

Hypertensive emergency is a common clinical entity with a wide variety of clinical manifestations with life threatening adverse outcomes if not recognized and acted upon immediately. Management is challenging as despite the availability of several drugs, their universal use is somewhat limited by side effects, ease of administration or availability. Unfortunately due to the nature of the disease and acuity of presentation it is difficult to conduct prospective randomized trials and hence there is a clear paucity of data in this field regarding the choice of medication and rate of lowering blood pressure in each clinical situation. Clevidipine, a recently approved drug appears to be safe and promising to use. For now, the choice of appropriate agent is based on end organ damage at presentation, mechanism of action and potential side effects of each medication, their availability and institutional culture.

\section{References}

1. Centers for Disease Control and Prevention (CDC) (2011) Vital signs: prevalence, treatment, and control of hypertension--United States, 1999-2002 and 2005-2008. MMWR Morb Mortal Wkly Rep 60: 103-108.

2. Aggarwal M, Khan IA (2006) Hypertensive crisis: hypertensive emergencies and urgencies. CardiolClin 24: 135-146.

3. Zampaglione B, Pascale C, Marchisio M, Cavallo-Perin P (1996) Hypertensive urgencies and emergencies. Prevalence and clinical presentation. Hypertension 27: $144-147$

4. Chobanian AV, Bakris GL, Black HR, Cushman WC, Green LA, et al. (2003) Seventh Report of the Joint National Committee on prevention, detection, evaluation and treatment of high blood pressure. Hypertension 42: 1206-1252.

5. Marik PE, Varon J (2007) Hypertensive crises: challenges and management Chest 131: 1949-1962.

6. Cherney D, Straus S (2002) Management of patients with hypertensive urgencies and emergencies: a systematic review of the literature. J Gen Intern Med 17: 937-945.

7. Pollack CV, Rees CJ (2008) Hypertensive Emergencies: Acute Care Evaluation and Management. Emergency Medicine Cardiac Research and Education Group 3.

8. Friederich JA, Butterworth JF 4th (1995) Sodium nitroprusside: twenty years and counting. AnesthAnalg 81: 152-162.

9. Robin ED, McCauley R (1992) Nitroprusside-related cyanide poisoning. Time (long past due) for urgent, effective interventions. Chest 102: 1842-1845.

10. Griswold WR, Reznik V, Mendoza SA (1981) Nitroprusside-induced intracranial hypertension. JAMA 246: 2679-2680.

11. Anile C, Zanghi F, Bracali A, Maira G, Rossi GF (1981) Sodium nitroprusside and intracranial pressure. ActaNeurochir (Wien) 58: 203-211.

12. Mann T, Cohn PF, Holman LB, Green LH, Markis JE, et al. (1978) Effect of nitroprusside on regional myocardial blood flow in coronary artery disease. Results in 25 patients and comparison with nitroglycerin. Circulation 57: 732 738.

13. Cohn JN, Franciosa JA, Francis GS, Archibald D, Tristani F, et al. (1982) Effect of short-term infusion of sodium nitroprusside on mortality rate in acute myocardial infarction complicated by left ventricular failure: results of a Veterans Administration cooperative study. N Engl J Med 306: 1129-1135.

14. Pasch T, Schulz V, Hoppelshäuser G (1983) Nitroprusside-induced formation of cyanide and its detoxication with thiosulfate during deliberate hypotension. $J$ Cardiovasc Pharmacol 5: 77-85.

15. Bussmann WD, Kenedi P, von Mengden HJ, Nast HP, Rachor N (1992) Comparison of nitroglycerin with nifedipine in patients with hypertensive crisis or severe hypertension. Clin Investig70: 1085-1088.

16. Lund-Johansen P (1984) Pharmacology of combined alpha-beta-blockade. II Haemodynamic effects of labetalol. Drugs 28 : $35-50$

17. Kanto J, Allonen H, Kleimola T, Mäntylä R (1981) Pharmacokinetics of labetalol in healthy volunteers. Int J ClinPharmacolTherToxicol 19: 41-44.

18. Marx PG, Reid DS (1979) Labetalol infusion in acute myocardial infarction with systemic hypertension. Br J ClinPharmacol 8: 233S-238S.

19. Olsen KS, Svendsen LB, Larsen FS, Paulson OB (1995) Effect of labetalol on cerebral blood flow, oxygen metabolism and autoregulation in healthy humans. $\mathrm{Br} \mathrm{J}$ Anaesth 75: 51-54.

20. Kanto J, Allonen H, Kleimola T, Mäntylä R (1981) Pharmacokinetics of labetalo in healthy volunteers. Int J Clin Pharmacol Ther Toxicol 19: 41-44.

21. Papadopoulos DP, Mourouzis I, Thomopoulos C, Makris T, Papademetriou V (2010) Hypertension crisis. Blood Press 19: 328-336.

22. Bodmann KF, Tröster S, Clemens R, Schuster HP (1993) Hemodynamic profile of intravenous fenoldopam in patients with hypertensive crisis. Clin Investig 72: $60-64$.

23. Munger MA, Rutherford WF, Anderson L, Hakki Al, Gonzalez FM, et al. (1990) Assessment of intravenous fenoldopammesylate in the management of severe systemic hypertension. Crit Care Med 18: 502-504. 
24. White WB, Radford MJ, Gonzalez FM, Weed SG, McCabe EJ, et al. (1988) Selective dopamine-1 agonist therapy in severe hypertension: effects of intravenous fenoldopam. J Am Coll Cardiol 11: 1118-1123.

25. Shusterman NH, Elliott WJ, White WB (1993) Fenoldopam, but not nitroprusside, improves renal function in severely hypertensive patients with impaired renal function. Am J Med 95: 161-168.

26. Elliott WJ, Weber RR, Nelson KS, Oliner CM, Fumo MT, et al. (1990) Rena and hemodynamic effects of intravenous fenoldopam versus nitroprusside in severe hypertension. Circulation 81: 970-977.

27. Tumlin JA, Dunbar LM, Oparil S, Buckalew V, Ram CV, et al. (2000) Fenoldopam, a dopamine agonist, for hypertensive emergency: a multicenter randomized trial. Fenoldopam Study Group. Acad Emerg Med 7: 653-662.

28. Schillinger D (1987) Nifedipine in hypertensive emergencies: a prospective study. J Emerg Med 5: 463-473.

29. Rodriguez G, Varon J (2006) Clevidipine: A unique agent for the critical care practitioner. Crit Care Shock; 9: 37-41.

30. Ericsson $\mathrm{H}$, Tholander $\mathrm{B}$, Regårdh CG (1999) In vitro hydrolysis rate and protein binding of clevidipine, a new ultrashort-acting calcium antagonist metabolised by esterases, in different animal species and man. Eur J Pharm Sci 8: 29-37.

31. Ericsson H, Fakt C, Jolin-Mellgård A, Nordlander M, Sohtell L, et al. (1999) Clinical and pharmacokinetic results with a new ultra short-acting calcium antagonist, clevidipine, following gradually increasing intravenous doses to healthy volunteers. $\mathrm{Br} \mathrm{J}$ ClinPharmacol47: 531-538

32. Barrett TW, Schriger DL (2009) Annals of Emergency Medicine Journa Club. Pollack CV, Varon J, Garrison NA, et al. Clevidipine, an intravenous dihydropyridine calcium channel blocker, is safe and effective for treatment of patients with acute severe hypertension. Ann Emerg Med 53: 339-340.

33. Pollack CV, Varon J, Garrison NA, Ebrahimi R, Dunbar L, et al. (2009) Clevidipine, an intravenous dihydropyridine calcium channel blocker, is safe and effective for the treatment of patients with acute severe hypertension. Ann Emerg Med 53: 329-338.

34. Levy JH, Mancao MY, Gitter R, Kereiakes DJ, Grigore AM, et al. (2007) Clevidipine effectively and rapidly controls elevated blood pressure preoperatively in cardiac surgery patients: the results of the randomized, placebo-controlled efficacy study of clevidipine assessing its preoperative hypertensive effect in cardiac surgery-1. AnesthAnalg105:918-925.

35. Singla N, Warltier DC, Gandhi SD, Lumb PD, Sladen RN, et al. (2008) Treatment of acute postoperative hypertension in cardiac surgery patients: an efficacy study of clevidipine assessing its postoperative antihypertensive effect in the cardiac surgery-2 (ESCAPE-2), a randomized, double-blind, placebocontrolled trial. AnesthAnalg107: 59-67.

36. Aronson S, Dyke CM, Stierer KA, Levy JH, Cheung AT, et al. (2008) The ECLIPSE trials: comparative studies of clevidipine to nitroglycerin, sodium nitroprusside, and nicardipine for acute hypertension treatment in cardiac surgery patients. Anesth Analg 107: 1110-1121.

37. Weder AB, Erickson S (2010) Treatment of hypertension in the inpatient setting use of intravenous labetalol and hydralazine. J Clin Hypertens (Greenwich) 12 29-33.

38. Shepherd AM, Ludden TM, McNay JL, Lin MS (1980) Hydralazine kinetics after single and repeated oral doses. Clin Pharmacol Ther 28: 804-811.

39. Marik PE, Rivera R (2011) Hypertensive emergencies: an update. Curr Opin Crit Care 17: 569-580.

40. Blumenfeld JD, Laragh JH (2001) Management of hypertensive crises: the scientific basis for treatment decisions. Am J Hypertens 14: 1154-1167.

41. Traon AP, Costes-Salon MC, Galinier M, Fourcade J, Larrue V (2002) Dynamics of cerebral blood flow autoregulation in hypertensive patients. J Neurol Sci 195: $139-144$
42. Eames PJ, Blake MJ, Panerai RB, Potter JF (2003) Cerebral autoregulation indices are unimpaired by hypertension in middle aged and older people. Am J Hypertens 16: 746-753.

43. Vaughan CJ, Delanty N (2000) Hypertensive emergencies. Lancet 356: 411 417 .

44. Hirschl MM (1995) Guidelines for the drug treatment of hypertensive crises Drugs 50: 991-1000.

45. Powers WJ (1993) Acute hypertension after stroke: the scientific basis for treatment decisions. Neurology 43: 461-467.

46. Adams HP Jr, Adams RJ, Brott T, del Zoppo GJ, Furlan A, et al. (2003) Guidelines for the early management of patients with ischemic stroke: $A$ scientific statement from the Stroke Council of the American Stroke Association. Stroke 34: 1056-1083.

47. Bath $P$ (2004) High blood pressure as risk factor and prognostic predictor in acute ischaemic stroke: when and how to treat it? Cerebrovasc Dis 17: 51-57.

48. Broderick JP, Adams HP Jr, Barsan W, Feinberg W, Feldmann E, et al. (1999) Guidelines for the management of spontaneous intracerebral hemorrhage: A statement for healthcare professionals from a special writing group of the Stroke Council, American Heart Association. Stroke 30: 905-915.

49. Kraus JJ, Metzler MD, Coplin WM (2002) Critical care issues in stroke and subarachnoid hemorrhage. Neurol Res 24: S47-57.

50. Sen J, Belli A, Albon H, Morgan L, Petzold A, et al. (2003) Triple-H therapy in the management of aneurysmal subarachnoid haemorrhage. Lancet Neurol 2 614-621.

51. Chen K, Varon J, Wenker OC, Judge DK, Fromm RE Jr, et al. (1997) Acute thoracic aortic dissection: the basics. J Emerg Med 15: 859-867.

52. Elliott WJ (2004) Clinical features and management of selected hypertensive emergencies. J Clin Hypertens (Greenwich) 6: 587-592.

53. ACOG Committee on Obstetric Practice (2002) ACOG practice bulletin Diagnosis and management of preeclampsia and eclampsia. Number 33, January 2002. American College of Obstetricians and Gynecologists. Int Gynaecol Obstet 77: 67-75.

54. Magee LA, Cham C, Waterman EJ, Ohlsson A, von Dadelszen P (2003) Hydralazine for treatment of severe hypertension in pregnancy: meta-analysis. BMJ 327: 955-960.

55. Pickles CJ, Broughton Pipkin F, Symonds EM (1992) A randomised placebo controlled trial of labetalol in the treatment of mild to moderate pregnancy induced hypertension. Br J Obstet Gynaecol 99: 964-968.

56. Jannet D, Carbonne B, Sebban E, Milliez J (1994) Nicardipine versus metoprolo in the treatment of hypertension during pregnancy: a randomized comparative trial. Obstet Gynecol 84: 354-359.

57. Carbonne B, Jannet D, Touboul C, Khelifati Y, Milliez J (1993) Nicardipine treatment of hypertension during pregnancy. Obstet Gynecol 81: 908-914. 